\title{
И.Ю. Понкратова*
}

\section{НАЧАЛЬНЫЙ НЕОЛИТ ПОЛУОСТРОВА КАМЧАТКА (ПО ДАННЫМ ИССЛЕДОВАНИЯ СТОЯНКИ УШКИ У)**}

\begin{abstract}
По результатам исследования раннеголоценового культурного слоя V стоянки Ушки V начальный неолит полуострова Камчатка датирован временем около 8500 кал. л.н. Комплекс каменной индустрии представлен одно - и двухплощадочными со встречным снятием пластин призматическими нуклеусами, бифасиальными изделиями, отщепами и пластинами со следами утилизации, ножами и концевыми скребками на пластинах, галечными орудиями. Одна из возможных инноваций эпохи - использование собак в упряжке в качестве средства передвижения. Прослежены связи населения с Приамурьем и арктической частью Сибири через континентальные районы Якутии.
\end{abstract}

Ключевые слова: начальный неолит, Ушки V, обсидиан, орудия на пластинах, скребки, упряжное собаководство

The Early Neolithic of the Kamchatka Peninsula: a study of Ushki V site. IRINA Yu. PONKRATOVA (North-Eastern State University)

According to the results of the study of the Early Holocene cultural layer $\mathrm{V}$ of Ushki V site the Early Neolithic of the Kamchatka Peninsula is dated to c. 8500 cal. BP. The industry is represented by single - and double-platform prismatic cores with counter removal of blades, bifacial tools, flakes and blades with traces of recycling, knives and end-scrapers on the blades, pebble tools. One of the possible innovations of the period could have been the use of dog sleds as a means of transportation. The local population could have had contacts with the people of the Amur region and the Arctic part of Siberia through the continental regions of Yakutia.

Keywords: Early Neolithic, Ushki V, obsidian, tools on the blades, scrapers, dog sled

В хронологии археологических культур и памятников полуострова Камчатка эталонными считаются многослойные стоянки Ушки, исследованные во второй половине XX в. Н.Н. Диковым. Выявленные на стоянках семь культурных слоев были определены исследователем как верхнепалеолитические (слои VII-V) и неолитические (слои IV-I) [3; 4; 5]. Культурный слой $\mathrm{V}$ был обнаружен при исследовании стоянок Ушки I, II, V на глубине 1,3-1,5 м. Жилища это-

* ПОНКРАТОВА Ирина Юрьевна, кандидат исторических наук, доцент кафедры всеобщей истории и истории России Северо-Восточного государственного университета.

E-mail: ponkratova1@yandex.ru

(C) Понкратова И.Ю., 2019

**Автор выражает благодарность И. Клаузену, М. Вебер, А. Сиглофу (Германия) за совместную работу в полевых и лабораторных условиях, возможность получения радиоуглеродных дат, а также В.В. Пономаревой, М.М. Певзнер, И.В. Мелекесцеву за консультации при идентификации вулканических пеплов и Пархомчук Е.В. (НГУ), Пархомчук В.В. (ИЯФ СО РАН), Растигееву С.А. (ИЯФ СО РАН) за проведение радиоуглеродного датирования образцов. 


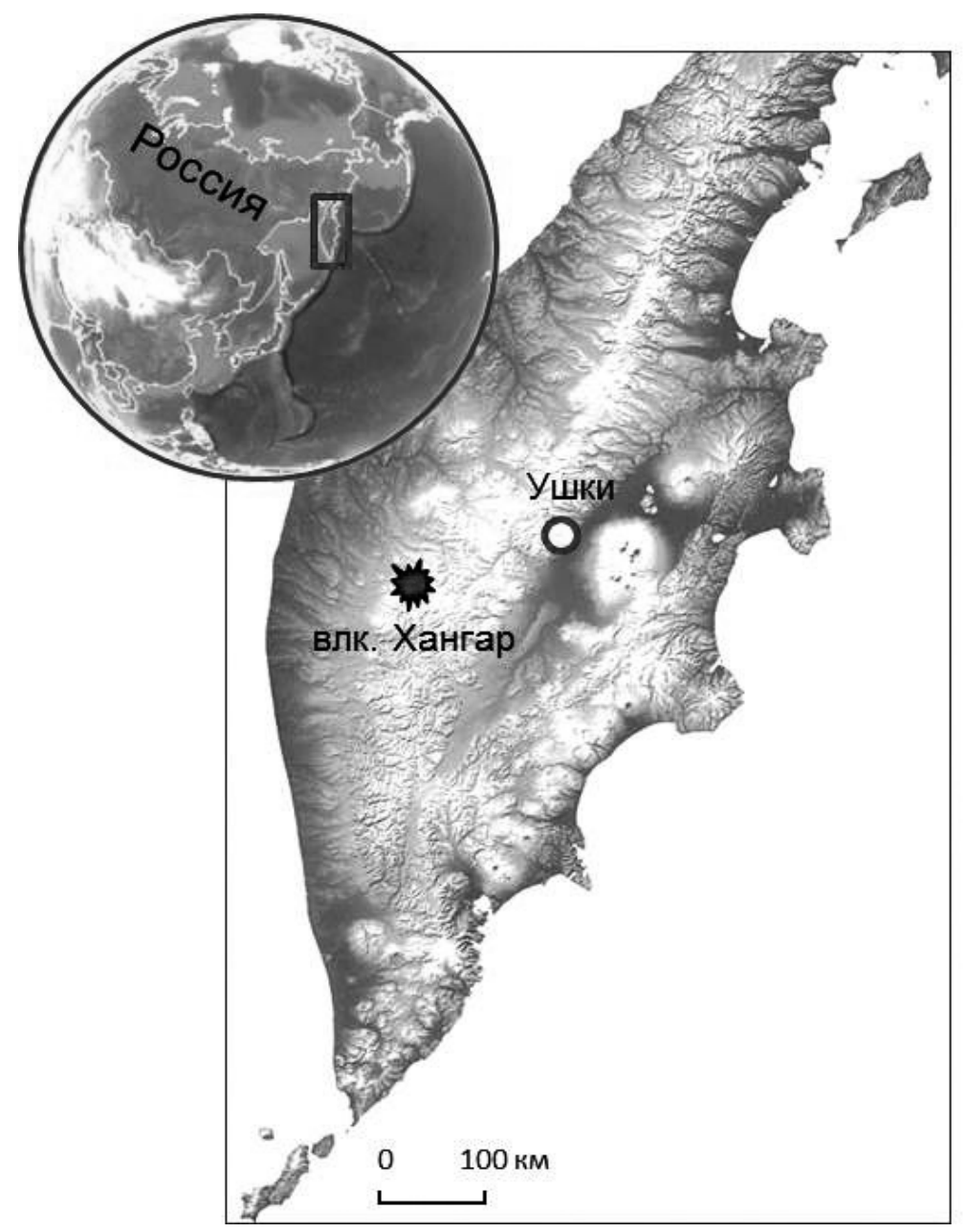

Pис. 1. Местонахождение на полуострове Камчатка (за основу взята цифровая модель рельефа, полученная NASA/JPL/NIMA) упоминаемых стоянок Ушки и вулкана Хангар

го слоя интерпретированы как наземные в виде шалашей, с очагами с кольцевой выкладкой из камней. Материальный комплекс, включающий каменные бифасиальные листовидные наконечники копий и стрел, скребки концевые грушевидной формы и короткие «невыработанной формы», резцы и ножи-бифасы, нуклеусы «невыработанной подпризматической и подконусовидной формы», микропластинки и отщепы,

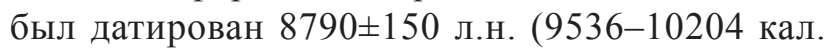
л.н. $)^{1}$ и интерпретирован как раннеголоценовый «финальный палеолит». Отмечалась «деградация в технологии ... комплекса», «отсутствие украшений» $[3$, с. $68 ; 5$, с. $32,35,36]$.

В 2004-2011 гг. изучение стоянок было продолжено раскопками стоянки Ушки V археологической экспедицией Северо-Восточного государственного университета (г. Магадан) под руководством автора. В результате исследова-

1 Здесь и далее переход на календарный возраст осуществлялся нами с помощью CALIB RADIOCARBON CALIBRATION PROGRAM [18]. ний с использованием стратиграфического, тефрохронологического, радиоуглеродного методов, изучения материальных комплексов и пр. обнаружены свидетельства четырех этапов заселения стоянки в конце плейстоцена - раннем голоцене: переходного от палеолита к неолиту периода (два этапа: 13300-12500 кал. л.н. и 12000-10100 кал. л.н.), начального ( 8600-8400 кал. л.н.) и раннего ( 7000-5000 кал. л.н.) неолита. Предметом данной публикации является введение в научный оборот и интерпретация материалов, связанных с третьим этапом заселения - эпохой начального неолита (культурный слой V).

Стоянка Ушки V, как и остальные стоянки Ушки, распложена на южном берегу Большого Ушковского озера - на разновысокой окраине пьедестала крупной и высокой конусообразной вулканической постройки Ключевской группы вулканов, перекрытой ледниковыми флювиогляциальными и пролювиальными рыхлыми осадками (Рис. 1). Стоянка находятся на высоте 37 м над уровнем моря и от 3 до 5 м - над уровнем реки. 


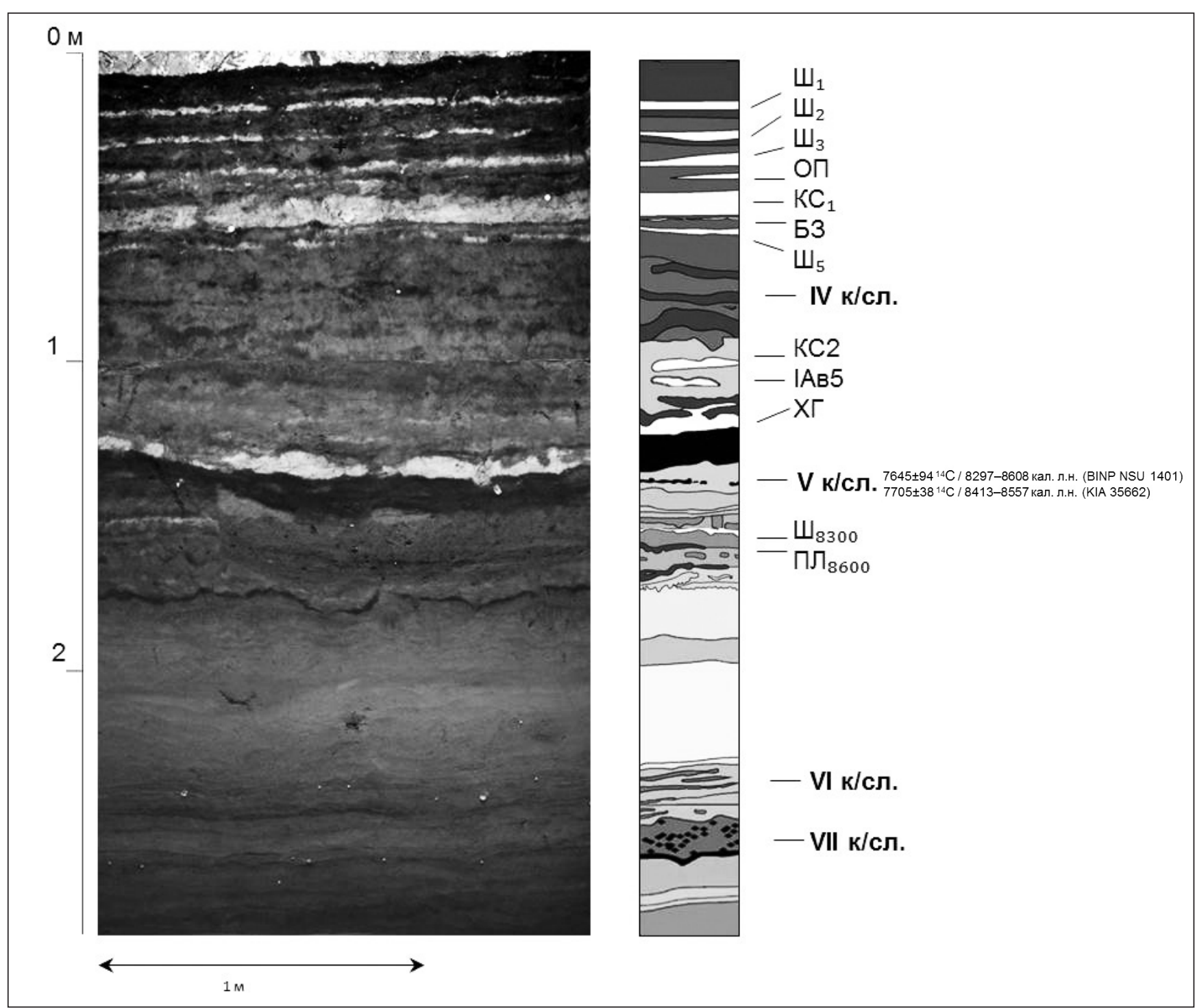

Puc. 2. Тефростратиграфия стоянки Ушки V с указанием маркеров и индексов вулканических извержений (по: [15]) и исследованных культурных слоев

Культурный слой V обнаружен в раннеголоценовых отложениях под непотревоженным пеплом вулкана Хангар (желто-коричневый суглинок с мелкозернистым песком, извержение $6957 \pm 30$ (6900) ${ }^{14} \mathrm{C} / 7694-7853$ кал. л.н.) [11, c. 231]) в темном коричнево-черном слегка запесоченом суглинке на глубине 1,3-1,5 м. Мощность слоя - от 10 до 20 см (Рис. 2). Из гумусированного слоя черного цвета между пеплом и отложениями культурного слоя по углю получены даты: 7705 \pm 38 (KIA 35662) ${ }^{14} \mathrm{C} / 8413$ 8557 кал. л.н., $7645 \pm 94{ }^{14} \mathrm{C} / 8297-8608$ кал. л.н. (BINP NSU 1401). Это время, когда на Камчатке происходила ландшафтная перестройка: холодные тундростепи сменили болотистые тундры, растительность которых составили карликовая береза, ольховник, василистник скрученный, редкоцветковый, плауны, зеленые мхи, водные растения из семейства рогозовых. Климат стал мягким, влажным [9]. На это время приходится мощная вспышка вулканической активности, названная «веком катастроф» [11]. В этот период формировалась первая надпойменная терраса с покровными отложениями и вулканическими пеплами [14]. Произошло уменьшение площади заселения по сравнению с предыдущим периодом [5, с. 32-36].

На стоянке Ушки $\mathrm{V}$ в раскопе площадью $24 \mathrm{~m}^{2}$ была исследована часть жилищного котлована с крутым склоном и почти горизонтальным дном, размером 4х3 м, в заполнении которого - перемешанный гумус с угольками, артефактами, частичками белого цвета (остатки костей?) ${ }^{2}$.

2 Другая часть котлована была раскопана при закладке шурфа российско-американской экспедицией в 2000 г. [16]. 
На изученной части жилища обнаружены нуклеусы, пластины, отщепы и орудия на пластинах из обсидиана черного и прозрачного цвета, кремня, гальки и сколы из халцедона, базальта и песчаника (Рис. 3).

Нуклеусы - призматические одно - и двухплощадочные со встречным снятием пластин (Рис. 3, № 1, 2). Отщепы и пластины классифицируются по размеру: крупные (более $5 \mathrm{~cm}$ в длину); средние (от 2 до 5 см); мелкие (менее 2 см); по виду огранки вентрала: продольные; бипродольные; дорсально-гладкие; радиальные; бессистемные (Рис. 3, № 12-16, 19-21). Часть отщепов (преимущественно 3-5 см в длину, 1-2 см в ширину) имеет следы утилизации, что свидетельствует о возможном их использовании в качестве режущих инструментов. Бифасиальные орудия - овальных форм из обсидиана черного цвета, со следами утилизации по краю (Рис. 3, № 3, 4, 11). Два фрагмента орудия из кремня и обсидиана, возможно, использовались как сверла (Рис. 3, № 9, 10). На одном галечном орудии из базальта отмечены следы ударов - не исключено его применение в качестве отбойника (Рис. 3, № 26). Другая галька могла использоваться как ретушер (Рис. 3, № 17). Скребки из обсидиана - концевые, изготовлены на пластинах и отщепах (Рис. 3, № 5-8). Кроме того, встречены сколы из обсидиана (Рис. 3, № 22, 23), галька и сколы из халцедона (Рис. 3, № 24, $25)$, плитка песчаника, возможно, используемая в качестве скребловидного орудия (Рис. 3 , № 18). Часть изделий из обсидиана покрыта патиной; на кремневых орудиях имеются следы термического воздействия.

Анализ расположения артефактов свидетельствует о возможной «рабочей площадке» на исследованной территории. Не исключено, что здесь же происходила разделка туш животных.

На Камчатке аналоги материалам культурного слоя V имеют место в комплексе слоя I стоянки Анавгай II, которая находится на расстоянии около 60 км на юго-запад от стоянок Ушки. В «неолитическом комплексе», залегавшем под пеплом вулкана Хангар, обнаружены «крупные ножевидные пластины шириной более $1,0 \mathrm{~cm}$ и их обломки с участками ретуши, концевые скребки, пластины с резцовыми сколами, крупные оббитые куски обсидиана (бифасы)» [12, c. 58,59$]$.

Наиболее ранние связи описанному комплексу каменных изделий предполагаем в археологических комплексах новопетровской культуры Западного Приамурья (12630-8590 л.н.)
$[8$, c. 105,107$]$ и на о. Сахалин (Огоньки 5, гор. 1, 13000-11000 л.н., ст. Костромское, ранний неолит) [1, с. 315, 362]. Аналоги встречены в использовании одно-, двухплощадочных призматических нуклеусов для снятия пластин и изготовлении орудий на пластинах и отщепах (скребки, вкладыши). Анализ радиоуглеродных дат комплексов памятников Дальнего Востока позволяет предположить, что заселение стоянки в этот период могло произойти со стороны Приамурья через побережья Охотского моря и Пенжинской губы. Эта предположение находит подтверждение и в этнографических описаниях Г.В. Стеллера, который, рассуждая о происхождении предков ительменов Камчатки, указывает на сходство их внешнего облика и языка с монголами и китайцами [13, с. 147-149].

Более поздние по времени, но схожие по облику и материалу аналоги ножевидных пластин комплекса культурного слоя V стоянки Ушки находим в материалах стоянки на о. Жохова, датируемых около 8000 кал. л.н. [2; 10; 17]. Находки костей собак, фрагменты нарт в охотничьем лагере на о. Жохова позволяют предположить, что путь с Камчатки в арктическую часть Сибири мог быть проделан на собаках в упряжке. От ушковских стоянок до о. Жохова по прямой линии около 2250 км. В XVIII в. между Камчаткой и Якутией действовали Якутско-Охотский, Охотско-Петропавловский тракты, протяженностью более 2600 км [7]. Не исключаем, что этот путь был известен населению и ранее. Причиной миграции могло стать катастрофическое извержение вулкана Хангар, которое сопровождалось сильным пожаром и пеплопадом, накрывшим около 7694-7853 кал. л.н. почти всю северо-восточную часть Камчатки [11, c. 231]. Езда на собаках упоминается и в мифах народов Камчатки, в которых говорится, что ворон Кутх - «создатель народа, первопредок» ездил по небу на собаках $[6$, с. 138]. Г.В. Стеллер считал нарты, устроенные «настолько по всем правилам механики, что их лучше не могли бы придумать ни Архимед, ни Христиан Вольф» [13, с. 146], выдающимся изобретением ительменов. В XVIII - первой половине XIX вв. ительмены пользовались уже двумя видами изготавливаемых из березы и кожаных ремней нарт - ездовыми и грузовыми (Рис. 4) [6, с. 69].

Таким образом, на основании проведенного исследования можно сделать следующие заключения. Содержащий артефакты раннеголоценовый культурный слой $\mathrm{V}$ стоянки Ушки $\mathrm{V}$, датируемый около 8500 кал. л.н., залегает выше 


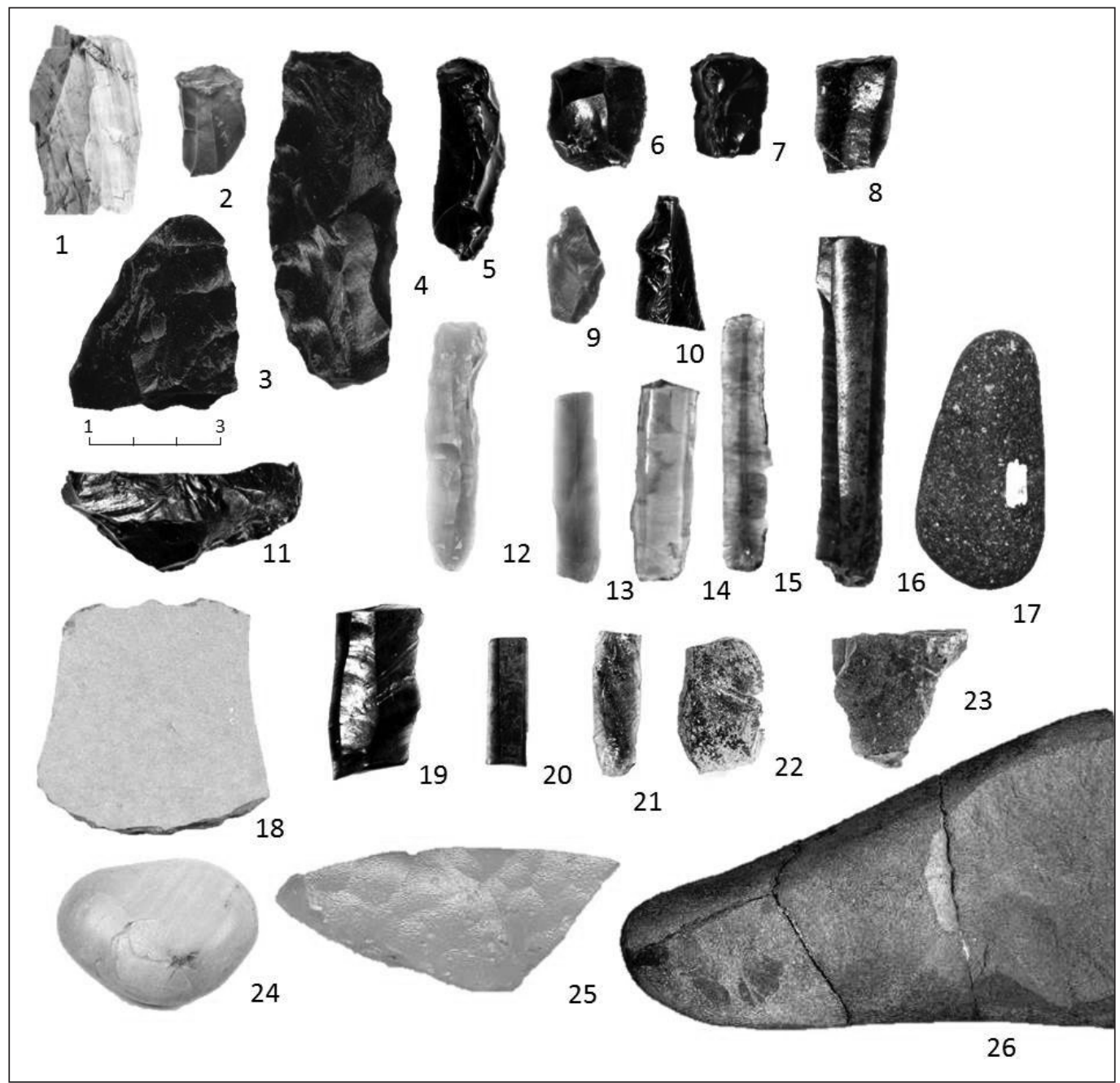

Puc. 3. Каменные артефакты культурного слоя V стоянки Ушки V (начальный неолит, полуостров Камчатка)

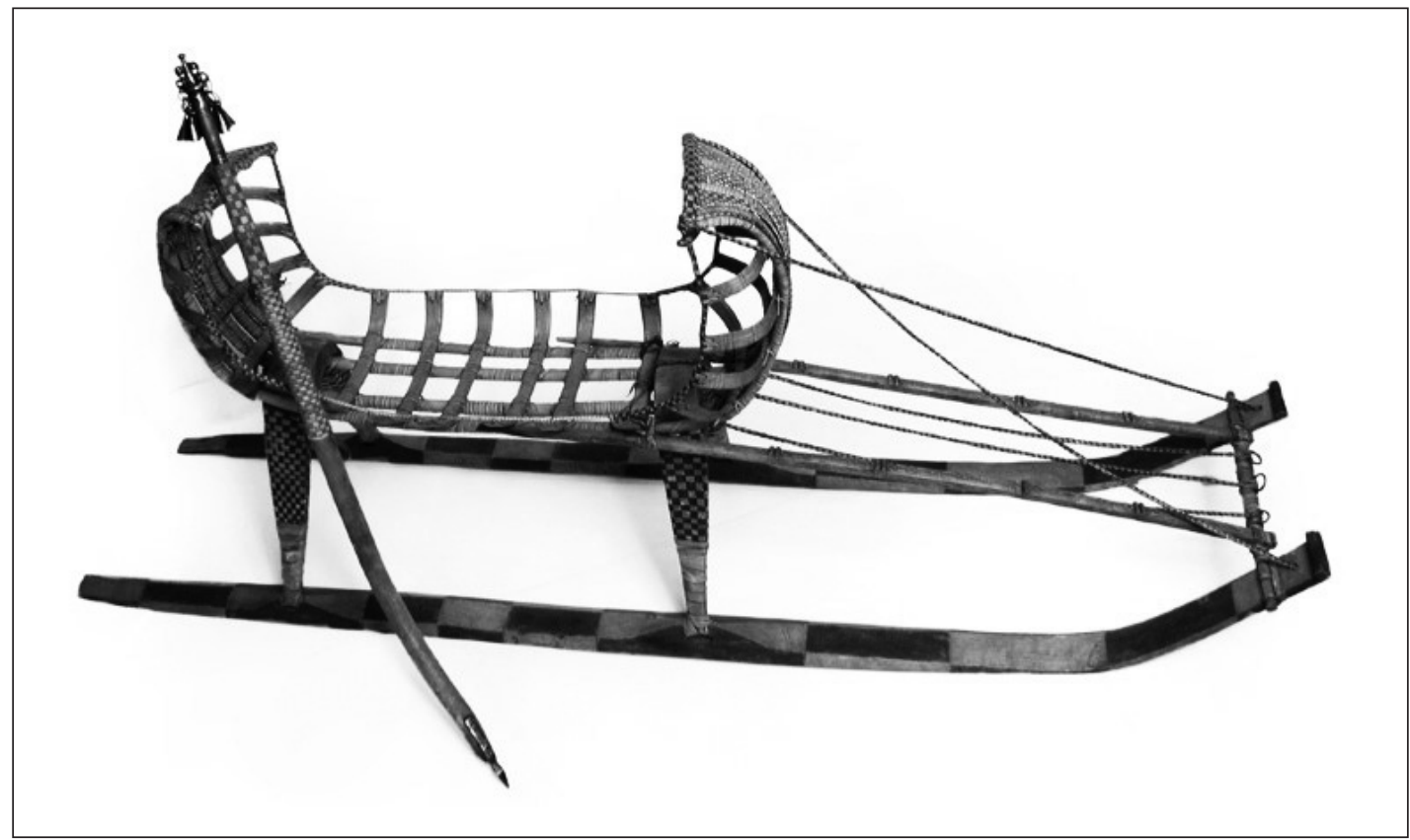

Puc. 4. Модель саней с упряжью. Северо-Восточная Сибирь. Ительмены. Начало ХІХ в. Дерево, кожа, железо, серебро. МАЭ РАН. № 20-16 
отложений предыдущего - переходного от палеолита к неолиту этапа (13300-10100 кал. л.н.) и непосредственно под слоем пепла катастрофического извержения вулкана Хангар (76947853 кал. л.н.).

Период раннего голоцена на Камчатке - время ландшафтной перестройки: смены холодных тундростепей болотистыми тундрами с более мягким и влажным климатом, что, возможно, было связано с активизацией вулканической деятельности на полуострове [11, с. 232]. В свою очередь, последствия катастрофического извержения Хангар могли стать причиной миграции древнего населения в более безопасные для проживания районы.

Маркирующим эпоху начала неолита на Камчатке может быть комплекс каменной индустрии, состоящий из одно - и двухплощадочных со встречным снятием пластин призматических нуклеусов, бифасиальных изделий, отщепов и пластин со следами утилизации, ножей и концевых скребков на пластинах, галечных орудий. Инновации эпохи начального неолита прослеживаются в появлении орудий на пластинах (скребки, ножи) и распространении вкладышевой техники изготовления орудий.

Появление упряжного собаководства, получившего широкое распространение на Камчатке в XVII - начале XX вв., может быть датировано начальным неолитом или временем около 8500 кал. л.н. Не исключено, что собак стали использовать для езды в упряжке и ранее: останки одомашненной собаки лайковидной породы датированы около 12000-10100 кал. л.н. [3; 4; 5].

Поиск аналогий позволяет проследить генетические связи населения с Приамурьем и его миграции в арктическую часть Сибири через континентальные районы Якутии.

Перспективными направлениями исследования представляются сравнительный анализ химического состава обсидиановых изделий со стоянок о. Жохова и Ушки V (культурный слой $\mathrm{V})$, выявление аналогов в конструкциях нарт Жоховской стоянки и этнографических описаниях ительменских нарт, используемых для упряжки собак, поиск раннеголоценовых стоянок по возможным путям передвижения населения (восточное и западное побережья Охотского моря).

\section{СПИСОК ЛИТЕРАТУРЫ}

1. Василевский А.А. Каменный век острова Сахалин. Южно-Сахалинск: Сахалин. кн. изд-во, 2008.
2. Гиря Е.Ю., Лозовский В.М. Сравнительный морфологический анализ полноты технологических контекстов каменных индустрий // Каменный век: от Атлантики до Пацифики: Замятнинский сборник. Вып. 3. СПб.: МАЭ РАН; ИИМК РАН, 2014. С. 52-84.

3. Диков Н.Н. Археологические памятники Камчатки, Чукотки и Верхней Колымы. Азия на стыке с Америкой в древности. М.: Наука, 1977.

4. Диков Н.Н. Древние культуры Северо-Восточной Азии. Азия на стыке с Америкой в древности. М.: Наука, 1979.

5. Диков Н.Н. Палеолит Камчатки и Чукотки в связи с проблемой первоначального заселения Америки. Магадан: СВКНИ ДВО РАН, 1993.

6. История и культура ительменов. Историко-этнографические очерки. Л.: Наука, 1990.

7. Казарян П.Л. Сухопутные сообщения Северо-Восточной России (XVII в. - 1920 гг.). Якутск: Изд. дом СВФУ, 2012.

8. Кузьмин Я.В., Нестеров С.П. Хронология неолитических культур Западного Приамурья // Традиционная культура Востока Азии. Вып. 6. Благовещенск: АмГУ, 2010. С. 103-110.

9. Ложкин А.В., Матросова Т.В., Корзун Ю.А. К палинологической характеристике отложений Ушковской стоянки на Камчатке // Пространственная и временная изменчивость природной среды северо-восточной Азии в четвертичный период. Магадан: СВКНИИ ДВО PAH, 2004. C. 98-105.

10. Макеев В.М., Питулько В.В., Каспаров А.К. Природная среда архипелага Де-Лонга в конце плейстоцена - начале голоцена и древний человек // Известия Русского географического общества. 1992. Т. 124. Вып. 3. С. 271-276.

11. Пономарева В.В., Мелекесцев И.В., Базанова Л.И., Биндеман И.Н., Леонов В.Л., Сулержицкий Л.Д. Вулканические катастрофы на Камчатке в среднем плейстоцене-голоцене // Экстремальные природные явления и катастрофы. Т. 1. М.: ИФЗ РАН, 2010. С. 219-238.

12. Пташинский А.В. Новые микропластинчатые комплексы периода финального палеолита на Камчатке // Вестник КРАУНЦ. Гуманитарные науки. 2012. № 1. С. 48-68.

13. Стеллер Г.В. Описание земли Камчатки. Петропавловск-Камчатский: Книжное изд-во, 1999.

14. Титов Э.Э., Казакова Г.П. Геоморфология и условия накопления рыхлых осадков на многослойной археологической стоянке Ушки V (Центральная Камчатка) // Новейшие данные по археологии Севера Дальнего Востока. Магадан: СВКНИИ ДВНЦ АН СССР, 1985. С. 24-34. 
15. Braitseva, O.A., Ponomareva, V.V., Sulerzhitsky, L.D., Melekestsev, I.V. and Bailey, J., 1997. Holocene key-marker tephra layers in Kamchatka, Russia. Quaternary Science Reviews, Vol. 47, no. 2, pp. 125-139.

16. Goebel, T., Waters, M. and Dikova, M., 2003. The archaeology of Ushki Lake, Kamchatka, and the Pleistocene peopling of the Americas. Science, Vol. 301, no. 5632, pp. 501-505.

17. Pitulko, V.V., Kuzmin, Y.V., Glascock, M.D., Pavlova, E.Yu. and Grebennikov, A.V., 2019. "They came from the ends of the earth»: long-distance exchange of obsidian in the High Arctic during the Early Holocene. Antiquity, Vol. 93, no. 367, pp. 28-44.

18. Reimer, P.J. et al., 2009. IntCal09 and Marine09 radiocarbon age calibration curves, 0-50,000 years cal BP. Radiocarbon, Vol. 51, no. 4, pp. 1111-1150.

\section{REFERENCES}

1. Vasilevskii, A.A., 2008. Kamennyi vek ostrova Sakhalin [Stone Age of Sakhalin Island]. Yuzhno-Sakhalinsk: Sakhalin. kn. izd-vo. (in Russ.)

2. Girya, E.Yu. and Lozovskii, V.M., 2014. Sravnitel'nyi morfologicheskii analiz polnoty tekhnologicheskikh kontekstov kamennykh industrii [Comparative morphological analysis of completeness of technological contexts of stone industries]. In: Kamennyi vek: ot Atlantiki do Patsifiki: Zamyatninskii sbornik. Vyp. 3. SanktPeterburg: MAE RAN; IIMK RAN, pp. 52-84. (in Russ.)

3. Dikov, N.N., 1977. Arkheologicheskie pamyatniki Kamchatki, Chukotki i Verkhnei Kolymy. Aziya na styke s Amerikoi v drevnosti [Archaeological sites of Kamchatka, Chukotka, and Upper Kolyma. Asia at the intersection with America in ancient times]. Moskva: Nauka. (in Russ.)

4. Dikov, N.N., 1979. Drevnie kul'tury SeveroVostochnoi Azii. Aziya na styke s Amerikoi v drevnosti [Ancient cultures of North-East Asia. Asia at the intersection with America in ancient times]. Moskva: Nauka. (in Russ.)

5. Dikov, N.N., 1993. Paleolit Kamchatki i Chukotki v svyazi s problemoi pervonachal'nogo zaseleniya Ameriki [The Paleolithic of Kamchatka and Chukotka in connection with the problems of peopling of America]. Magadan: SVKNI DVO RAN. (in Russ.)

6. Istoriya i kul'tura itel'menov. Istorikoetnograficheskie ocherki [History and culture of the Itelmen. Historical and ethnographic essays]. Leningrad: Nauka. (in Russ.)

7. Kazaryan, P.L., 2012. Sukhoputnye soobshcheniya Severo-Vostochnoi Rossii (XVII v. - 1920 gg.) [Land communications of NorthEastern Russia (XVII century - the 1920s)]. Yakutsk: Izd. dom SVFU. (in Russ.)

8. Kuzmin, Ya.V. and Nesterov, S.P., 2010. Khronologiya neoliticheskikh kul'tur Zapadnogo Priamur'ya [Chronology of Neolithic cultures of the Western Amur region]. In: Traditsionnaya kul'tura Vostoka Azii. Vyp. 6. Blagoveshchensk: AmGU, pp. 103-110. (in Russ.)

9. Lozhkin, A.V., Matrosova, T.V. and Korzun, Yu.A., 2004. K palinologicheskoi kharakteristike otlozhenii Ushkovskoi stoyanki na Kamchatke [Towards the palynological characteristics of Ushkovskaya site sediments in Kamchatka]. In: Prostranstvennaya i vremennaya izmenchivost' prirodnoi sredy severo-vostochnoi Azii v chetvertichnyi period. Magadan: SVKNII DVO RAN, pp. 98-105. (in Russ.)

10. Makeev, V.M., Pitul'ko, V.V. and Kasparov, A.K., 1992. Prirodnaya sreda arkhipelaga DeLonga $\mathrm{v}$ kontse pleistotsena - nachale golotsena i drevnii chelovek [The natural environment of De Long Islands at the end of the Pleistocene the beginning of the Holocene and ancient man], Izvestiya Russkogo geograficheskogo obshchestva, Vol. 124, no. 3, pp. 271-276. (in Russ.)

11. Ponomareva, V.V. etal., 2010. Vulkanicheskie katastrofy na Kamchatke $\mathrm{v}$ srednem pleistotsenegolotsene [Volcanic disasters in Kamchatka in the middle Pleistocene-Holocene]. In: Ekstremal'nye prirodnye yavleniya i katastrofy. T. 1. Moskva: IFZ RAN, pp. 219-238. (in Russ.)

12. Ptashinskii, A.V., 2012. Novye mikroplastinchatye kompleksy perioda final'nogo paleolita na Kamchatke [New microblade complexes of the final Paleolithic period in Kamchatka], Vestnik KRAUNTs. Gumanitarnye nauki, no. 1, pp. 48-68. (in Russ.)

13. Steller, G.V., 1999. Opisanie zemli Kamchatki [Description of the land of Kamchatka]. Petropavlovsk-Kamchatskii: Knizhnoe izdatel'stvo. (in Russ.)

14. Titov, E.E. and Kazakova, G.P., 1985. Geomorfologiya i usloviya nakopleniya rykhlykh osadkov na mnogosloinoi arkheologicheskoi stoyanke Ushki V (Tsentral'naya Kamchatka) [Geomorphology and conditions of accumulation of loose sediments on the multilayer archaeological site Ushki V (Central Kamchatka)]. In: Noveishie dannye po arkheologii Severa Dal'nego Vostoka. 
Magadan: SVKNII DVNTS AN SSSR, pp. 24-34.

(in Russ.)

15. Braitseva, O.A., Ponomareva, V.V., Sulerzhitsky, L.D., Melekestsev, I.V. and Bailey, J., 1997. Holocene key-marker tephra layers in Kamchatka, Russia. Quaternary Science Reviews, Vol. 47, no. 2, pp. 125-139.

16. Goebel, T., Waters, M. and Dikova, M., 2003. The archaeology of Ushki Lake, Kamchatka, and the Pleistocene peopling of the Americas.

Science, Vol. 301, no. 5632, pp. 501-505.
17. Pitulko, V.V., Kuzmin, Y.V., Glascock, M.D., Pavlova, E.Yu. and Grebennikov, A.V., 2019. «They came from the ends of the earth»: long-distance exchange of obsidian in the High Arctic during the Early Holocene. Antiquity, Vol. 93 , no. 367 , pp. $28-44$.

18. Reimer, P.J. et al., 2009. IntCa109 and Marine09 radiocarbon age calibration curves, 0-50,000 years cal BP. Radiocarbon, Vol. 51, no. 4, pp. 1111-1150.

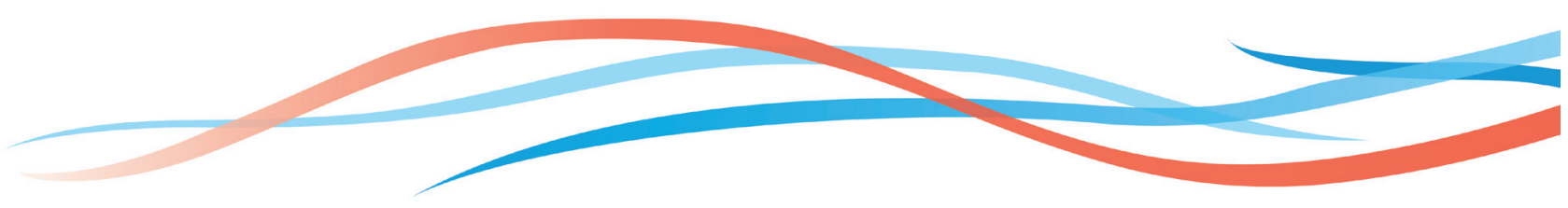

